\title{
Serious Conditions in COVID-19 Accompanied With a Feature of Metabolic Syndrome
}

\author{
Kei Nakajimaa, b, c, d
}

At the time of this writing, coronavirus disease 2019 (COVID-19) caused by the severe acute respiratory syndrome coronavirus 2 (SARS-CoV-2) strain of coronavirus has reached pandemic levels, threatening human life and limiting activity worldwide. For the past several months, the clinical characteristics of patients who are likely to develop a serious condition or die from COVID-19 have been gradually revealed from the evidence accumulated by great efforts of frontline health professionals and investigators worldwide [1-3].

Retrospective research has shown that COVID-19 is frequently observed in people with obesity, diabetes, and hypertension [1-13], which are pivotal components of metabolic syndrome (MetS), a cluster of cardiometabolic risks based on excess visceral fat. In addition, the condition and mortality of patients infected with SARS-CoV-2 are likely to be more serious in cases that involve a feature of MetS compared with cases that do not $[1,4-6,8,10-13]$. Hospitalization, admission to intensive care unit (ICU), and usage of mechanical ventilation are much more prevalent in patients with obesity $[4,5,14]$ and diabetes $[10,13]$, which are the fundamental components of MetS [15].

These facts are undeniable, and yet they may go unperceived by frontline health professionals and the general population alike. One plausible reason for this is that each component of MetS (obesity, diabetes, and hypertension) has been paid attention sporadically and separately in different fields, and not argued comprehensively even in the updated literature.

In recent decades, many investigators have convincingly shown that people with obesity, prediabetes, diabetes and MetS

Manuscript submitted April 27, 2020, accepted April 29, 2020

aSchool of Nutrition and Dietetics, Faculty of Health and Social Services, Kanagawa University of Human Services, 1-10-1 Heisei-cho, Yokosuka, Kanagawa 238-8522, Japan

${ }^{b}$ Graduate School of Health Innovation, Kanagawa University of Human Services, Research Gate Building Tonomachi 2-A, 3-25-10 Tonomachi, Kawasaki, Kanagawa 210-0821, Japan

'Department of Endocrinology and Diabetes, Saitama Medical Center, Saitama Medical University, 1981 Kamoda, Kawagoe, Saitama 350-8550, Japan

${ }^{\mathrm{d} C}$ Corresponding Author: Kei Nakajima, School of Nutrition and Dietetics, Faculty of Health and Social Services, Kanagawa University of Human Services, 1-10-1 Heisei-cho, Yokosuka, Kanagawa 238-8522, Japan.

Email: nakajima-rsh@kuhs.ac.jp

doi: https://doi.org/10.14740/jocmr4187 are at increased risk for impaired lung function, and especially impaired restrictive lung pattern [16-22], which is primarily determined by reduced predicted forced vital capacity. Chronic obstructive pulmonary disease, which is familiar to physicians and the general population, and usually determined by reduced forced expiratory volume in $1 \mathrm{~s}$, might play only a minor role in the physiology of impaired lung function observed in patients with MetS or diabetes [16-22].

Consistently, overweight and MetS have been shown to be associated with the severity of influenza A (H1N1) [2325], although the precise mechanism has not been explored. Therefore, it is reasonable to expect serious condition and high mortality in cases of COVID-19 accompanied by features of MetS because the main target organ of SARS-CoV-2 is the lung.

It is well established that the prevalence rates of MetS and obesity are higher in Americans and Europeans than in Asians [26, 27], which may explain some proportion of the observed differences in severity, hospitalization, and mortality rates of COVID-19 between Western and Asian countries. On the other hand, MetS is far more prevalent in men than in women $[1,2]$, is associated with chronic kidney disease $[28$, 29], and may be attributable to the same unknown mechanism mentioned above.

In patients with any of the specific metabolic abnormalities of MetS, pre-existing impaired lung function can predispose them to SARS-CoV-2 infection and even accelerate it, potentially worsening the condition. Plausible pathophysiology for this phenomenon includes impaired immune function, elevated inflammation, insulin resistance, restrictive pattern/ reduced lung volume, and elevated expression of receptors of angiotensin converting enzyme 2 (ACE2) and dipeptidyl peptidase 4 (DPP-4) $[2,6-8,10,12,14,30]$. The latter two of these may be particularly notable because the expression of ACE2, a receptor for the entry of SARS-CoV-2 into target cells, and DPP-4 are both increased in patients with obesity and diabetes $[6,12]$. Although it has not been definitively established that inhibitors of ACE and DPP-4 influence the predisposition and/or severity of SARS-CoV-2 [31,32], this possibility deserves further study.

Taken together, the predisposition to infection with viruses including SARS-CoV-2 may represent a serious complication when accompanied by any of the features of MetS, which are mostly preventable or modifiable by diet, exercise, and other aspects of a healthy lifestyle.

Urgent COVID-19 studies are required to confirm the association between serious condition and obesity and diabetes, 
investigate the fundamental features of MetS in terms of causality, and explore potential treatments for the multitude of patients all around the world.

\section{Acknowledgments}

We thank Michelle Kahmeyer-Gabbe, PhD, from Edanz Group (www.edanz.com/ac) for editing a draft of this manuscript.

\section{Financial Disclosure}

None to declare.

\section{Conflict of Interest}

None to declare.

\section{Data Availability}

The author declares that data supporting the findings of this study are available within the article.

\section{References}

1. Dietz W, Santos-Burgoa C. Obesity and its implications for COVID-19 mortality. Obesity (Silver Spring). 2020.

2. Balla M, Merugu GP, Patel M, Koduri NM, Gayam V, Adapa S, Naramala S. COVID-19, modern pandemic: a systematic review from front-line health care providers' perspective. J Clin Med Res. 2020;12(4):215-229.

3. Puig-Domingo M, Marazuela M, Giustina A. COVID-19 and endocrine diseases. A statement from the European Society of Endocrinology. Endocrine. 2020;68(1):2-5.

4. Ryan DH, Ravussin E, Heymsfield S. COVID 19 and the patient with obesity - the editors speak out. Obesity (Silver Spring). 2020;28(5):847.

5. Lighter J, Phillips M, Hochman S, Sterling S, Johnson D, Francois F, Stachel A. Obesity in patients younger than 60 years is a risk factor for Covid-19 hospital admission. Clin Infect Dis. 2020.

6. Kassir R. Risk of COVID-19 for patients with obesity. Obes Rev. 2020.

7. Maddaloni E, Buzzetti R. Covid-19 and diabetes mellitus: unveiling the interaction of two pandemics. Diabetes Metab Res Rev. 2020:e33213321.

8. Muniyappa R, Gubbi S. COVID-19 pandemic, coronaviruses, and diabetes mellitus. Am J Physiol Endocrinol Metab. 2020;318(5):E736-E741.

9. Klonoff DC, Umpierrez GE. COVID-19 in patients with diabetes: risk factors that increase morbidity. Metabolism. 2020:154224.

10. Singh AK, Gupta R, Ghosh A, Misra A. Diabetes in COVID-19: Prevalence, pathophysiology, prognosis and practical considerations. Diabetes Metab Syndr. 2020;14(4):303-310.

11. Hussain A, Bhowmik B, do Vale Moreira NC. COVID-19 and diabetes: Knowledge in progress. Diabetes Res Clin Pract. 2020;162:108142.

12. Fang L, Karakiulakis G, Roth M. Are patients with hypertension and diabetes mellitus at increased risk for COVID-19 infection? Lancet Respir Med. 2020;8(4):e21.

13. Drucker DJ. Coronavirus Infections and Type 2 DiabetesShared Pathways with Therapeutic Implications. Endocr Rev. 2020;41(3).

14. Simonnet A, Chetboun M, Poissy J, Raverdy V, Noulette J, Duhamel A, Labreuche J, et al. High prevalence of obesity in severe acute respiratory syndrome coronavirus-2 (SARS-CoV-2) requiring invasive mechanical ventilation. Obesity (Silver Spring). 2020.

15. Grundy SM, Cleeman JI, Daniels SR, Donato KA, Eckel RH, Franklin BA, Gordon DJ, et al. Diagnosis and management of the metabolic syndrome: an American Heart Association/National Heart, Lung, and Blood Institute Scientific Statement. Circulation. 2005;112(17):2735-2752.

16. Nakajima K, Kubouchi Y, Muneyuki T, Ebata M, Eguchi S, Munakata H. A possible association between suspected restrictive pattern as assessed by ordinary pulmonary function test and the metabolic syndrome. Chest. 2008;134(4):712-718.

17. Paek YJ, Jung KS, Hwang YI, Lee KS, Lee DR, Lee JU. Association between low pulmonary function and metabolic risk factors in Korean adults: the Korean National Health and Nutrition Survey. Metabolism. 2010;59(9):1300-1306.

18. Yoshimura C, Oga T, Chin K, Takegami M, Takahashi $\mathrm{K}$, Sumi K, Nakamura T, et al. Relationships of decreased lung function with metabolic syndrome and obstructive sleep apnea in Japanese males. Intern Med. 2012;51(17):2291-2297.

19. Li Y, Saito M, Tobimatsu S, Oshida H, Hori Y, Fuchigami H, Munakata H, et al. Prediabetes and impaired lung function in asymptomatic adults. Diabetes Res Clin Pract. 2013;100(2):e51-54.

20. Scarlata S, Fimognari FL, Cesari M, Giua R, Franco A, Pasqualetti P, Pastorelli R, et al. Lung function changes in older people with metabolic syndrome and diabetes. Geriatr Gerontol Int. 2013;13(4):894-900.

21. Kim CH, Kim HK, Kim EH, Bae SJ, Jung YJ, Choi J, Park JY. Association of restrictive ventilatory dysfunction with the development of prediabetes and type 2 diabetes in Koreans. Acta Diabetol. 2015;52(2):357-363.

22. Godfrey MS, Jankowich MD. The vital capacity is vital: epidemiology and clinical significance of the restrictive spirometry pattern. Chest. 2016;149(1):238-251.

23. Bijani B, Pahlevan AA, Qasemi-Barqi R, Jahanihashemi $\mathrm{H}$. Metabolic syndrome as an independent risk factor of hypoxaemia in influenza A (H1N1) 2009 pandemic. Infez Med. 2016;24(2):123-130.

24. Morgan OW, Bramley A, Fowlkes A, Freedman DS, Taylor TH, Gargiullo P, Belay B, et al. Morbid obesity as a risk factor for hospitalization and death due to 2009 pandemic influenza A(H1N1) disease. PLoS One. 2010;5(3):e9694. 
25. Martin V, Castilla J, Godoy P, Delgado-Rodriguez M, Soldevila N, Fernandez-Villa T, Molina AJ, et al. High body mass index as a risk factor for hospitalization due to influenza: a case-control study. Arch Bronconeumol. 2016;52(6):299-307.

26. Patel A, Huang KC, Janus ED, Gill T, Neal B, Suriyawongpaisal P, Wong E, et al. Is a single definition of the metabolic syndrome appropriate? A comparative study of the USA and Asia. Atherosclerosis. 2006;184(1):225232.

27. Pan WH, Yeh WT, Weng LC. Epidemiology of metabolic syndrome in Asia. Asia Pac J Clin Nutr. 2008;17(Suppl 1):37-42.

28. Emami A, Javanmardi F, Pirbonyeh N, Akbari A. Prevalence of underlying diseases in hospitalized patients with COVID-19: a systematic review and meta-analysis. Arch Acad Emerg Med. 2020;8(1):e35.
29. Henry BM, Lippi G. Chronic kidney disease is associated with severe coronavirus disease 2019 (COVID-19) infection. Int Urol Nephrol. 2020.

30. Carter SJ, Baranauskas MN, Fly AD. Considerations for obesity, vitamin D, and physical activity amidst the COVID-19 pandemic. Obesity (Silver Spring). 2020.

31. Sommerstein R, Kochen MM, Messerli FH, Grani C. Coronavirus disease 2019 (COVID-19): do angiotensin-converting enzyme inhibitors/angiotensin receptor blockers have a biphasic effect? J Am Heart Assoc. 2020;9(7):e016509.

32. Guo J, Huang Z, Lin L, Lv J. Coronavirus disease 2019 (COVID-19) and cardiovascular disease: a viewpoint on the potential influence of angiotensin-converting enzyme inhibitors/angiotensin receptor blockers on onset and severity of severe acute respiratory syndrome coronavirus 2 infection. J Am Heart Assoc. 2020;9(7):e016219. 